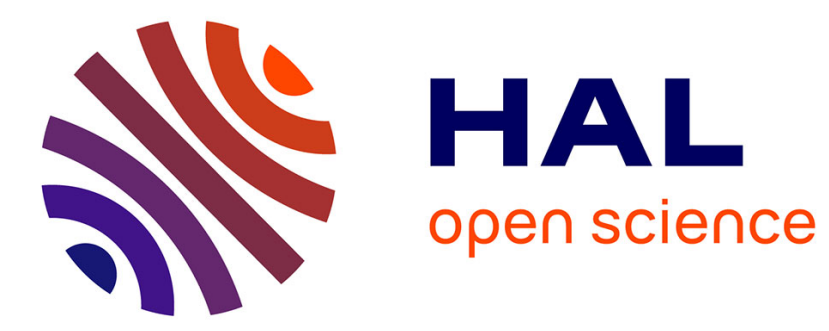

\title{
Influence of the Filler Type on the Rupture Behavior of Filled Elastomers
}

\author{
S. Gherib, Laurent Chazeau, Jean-Marc Pelletier, H. Satha
}

\section{To cite this version:}

S. Gherib, Laurent Chazeau, Jean-Marc Pelletier, H. Satha. Influence of the Filler Type on the Rupture Behavior of Filled Elastomers. Journal of Applied Polymer Science, 2010, 118 (1), pp.435445. 10.1002/app.31606 . hal-00539988

\section{HAL Id: hal-00539988 https://hal.science/hal-00539988}

Submitted on 25 Nov 2010

HAL is a multi-disciplinary open access archive for the deposit and dissemination of scientific research documents, whether they are published or not. The documents may come from teaching and research institutions in France or abroad, or from public or private research centers.
L'archive ouverte pluridisciplinaire HAL, est destinée au dépôt et à la diffusion de documents scientifiques de niveau recherche, publiés ou non, émanant des établissements d'enseignement et de recherche français ou étrangers, des laboratoires publics ou privés. 


\title{
Influence of the filler type on the rupture behavior of filled
}

\author{
elastomers
}

S. Gherib ${ }^{1,2}$, L. Chazeau ${ }^{1}$ a, J. M. Pelletier ${ }^{1}$, H. Satha ${ }^{2}$

1 Université de Lyon, INSA-Lyon, MATEIS UMR5510, Bâtiment Blaise Pascal, 20 Avenue Albert Einstein, F-69621 Villeurbanne Cedex, France

2 Faculté des Sciences et Sciences de l'ingénierie, Université 8 mai 1945 - Guelma, BP 401 Guelma 24000 - Algérie

\begin{abstract}
This work is devoted to the rupture behavior of elastomers filled with carbon black (CB) or silica. Two elastomers have been studied: one which crystallizes under strain, natural rubber (NR), and another one which does not crystallize, styrene butadiene rubber (SBR). The study of the crack propagation of Single Edge Notched specimen (SENT) during stretching at different speeds focused on the crack initiation and crack deviation phenomenon. This deviation is of main importance in the materials crack resistance since it leads to a large increase in the energy needed for rupture. The deviation in filled or unfilled NR is controlled by crystallization, which is a slow process. In unfilled SBR, deviation is controlled by polymer chain orientation, which is hindered by relaxation mechanisms. The introduction of fillers promotes strain amplification, and strain anisotropy in the crack tip region of the notched samples, and therefore crack deviation. In term of energy density at break of the SBR composites, the SBR filled with silica treated with a covering agent is the most efficient.
\end{abstract}

\footnotetext{
${ }^{a}$ Corresponding author : Laurent.Chazeau@insa-lyon.fr, Tél : +33 4724361 30, Fax : +33 472438528
} 
Thus, a weak interface between the silica and SBR promotes better rupture properties. When comparing Silica and CB filled NR, the highest strain energy to rupture is also obtained with silica. This might be due to the weaker filler-matrix interface for silica. Thus, these results evidence the kinetic aspect of the rupture, and of the mechanisms it involves: the polymer relaxation, the crystallization (for NR), and the filler-matrix interaction and decohesion, all of them being strongly interrelated.

Keywords: silica, carbon black, fracture, crack

\section{INTRODUCTION}

Elastomers are used in many applications where they are submitted to complex cyclic stresses. Such cyclic stresses, in addition to severe environmental conditions, lead to the material ruin either by progressive wear, or by catastrophic failure ${ }^{1}$. In both cases, this ruin is the result of rupture mechanisms either localized, or macroscopic. Such a rupture obviously depends on the material resistance to crack propagation. For this reason, crack tests have been early defined as an evaluation test of elastomer material. Many types of crack test exist in literature, among them non cyclic or cyclic tests performed on single or double edge notched

sample, with different possible geometries ${ }^{2,3,4}$. Thus, many experimental data obtained from crack tests performed on elastomer materials can be found in literature. From these data, one can extract different parameters important for the crack resistance.

Elastomer crack resistance is strongly dependent on the material formulation and its processing. A first parameter easily identified is the elastomer nature. Elastomers can be 
natural or synthetic. Natural rubber (NR) (poly isoprene cis-1,4), which is widely used in industry, differs from the most common synthetic elastomers such as Acrylo-Nytril butadiene (NBR) or Styrene butadiene (SBR) by its ability to crystallize under strain. This phenomenon has been observed in the early 30's by Busse ${ }^{5}$. He attributed the crack rotation observed during the tests to the development of crystallites in the crack tip. Thus, crystallites, by supporting a high stress level, are obstacles to the crack propagation ${ }^{6}$. As soon as 1947 , Flory ${ }^{6,7}$ physically explained the phenomenon. Different authors have then studied the influence of the notch geometry or the strain rate on the crack propagation in $\mathrm{NR}^{9-13}$. The crystallization in the crack tip has been more particularly studied by Trabelsi et al. ${ }^{14}$ using local Small Angle X rays (SAXS) measurements. They showed four regions in the crack vicinity: a crystallized one at the crack tip, where the elongation is the highest, a transition zone where the crystallinity is decreasing, when going far from the crack, an extended non crystallized zone and a totally relaxed zone. For an identification of the material parameters important for the Strain Induced Crystallization (SIC), recent studies used synchrotron X-rays facilities to characterize the crystallites formed during tensile tests ${ }^{15-17}$. They have shown that the crosslink density is a key parameter of the phenomenon, the optimal chemical crosslink density, i.e. the one which leads to the highest crystallization rate, being of the order of the NR entanglement density. In the case of non crystallisable unfilled elastomer, crack rotation is generally not observed, though the stretched polymer chains in the crack tip can also act as an obstacle to crack propagation.

Elastomers being most of the time reinforced by nanoscopic fillers, another parameter immediately identified in the material crack resistance is the filler dispersion. A very bad one would lead, like for all composites, to a decrease of the material properties, and in particular to crack initiation in the vicinity of the filler agglomerates. Hopefully, the dispersion of the nanoscopic fillers usually used in elastomer material is now correctly achieved. It leads to a 
fractal structure of fillers in the materials with absence of big agglomerates responsible of crack initiation. Actually, the main role of the filler is to locally amplify the strain, as shown in the study performed on filled $\mathrm{NR}{ }^{17}$, leading to an earlier material crystallization, i.e. an earlier crack rotation during stretching. Moreover, as shown by in situ volume variation measurements ${ }^{17,18}$, the presence of fillers also leads to voids formation more or less initiated by the particles, depending on the filler-matrix interaction. This has necessarily consequences in the material stress hardening, and the development of local stress anisotropy. Thus, strong interfaces can facilitate anisotropy development in the crack vicinity, which are expected to favor the crack resistance of the material.

The improvement of the crack resistance induced by the addition of carbon blacks (CB) is well documented by the study of Hamed et al. ${ }^{19-23}$. In the experimental conditions they used, unfilled NR does not show crack rotation, while CB filled NR shows a longitudinal crack propagation before the sample rupture. Interestingly, the addition of carbon black can also strongly enhance the crack resistance of SBR ${ }^{24}$. Moreover, Borret ${ }^{25}$ has shown that this material, though its non crystallisable nature, can also show crack rotation in certain conditions of strain rate and temperature. Thus, crack rotation does not necessarily require the polymer crystallization, and the development of local anisotropy is seemingly sufficient.

If the crack resistance of $\mathrm{CB}$ filled elastomer is often reported, whether the elastomer is $\mathrm{NR}^{26}$ or synthetic rubber ${ }^{27}$, in contrast, to the author's knowkledge, very few studies have been reported on the impact of the addition of nanoscopic silica in the crack resistance of NR or synthetic rubber. Such filler has a different surface than $\mathrm{CB}$, and therefore develops different interactions with the polymer matrix. Reincke et al. ${ }^{28}$ very recently studied SBR filled with both filler types. The silica they used was previously treated with silane to enable covalent bond formation between the silica and the polymer. Both filler types led to a large increase in crack resistance. However, differences were found in their influence on the 
resistance to crack propagation in quasi-static tests, attributed to the different time-dependent behaviour of the composites. In the case of a NR matrix, Reincke et al. showed that silica, like CB fillers, strongly improve toughness. ${ }^{29}$ However, no comparison was done with $\mathrm{CB}$ filled NR. In addition, these works interestingly pointed out the different influence of the fillers on the crack initiation and on the crack propagation, but did not discussed the impact of the fillers on the crack deviation during its propagation. Thus, the objective of this paper is to present an experimental study of the crack resistance of SBR and NR filled with nanoscopic silica fillers. Their impact is compared with that of $\mathrm{CB}$, for which results are also presented. Such a work was strongly motivated by all the previous work performed in the laboratory on the characterization of the same type of materials, the presented study being performed on samples with formulation inspired from references ${ }^{15-18}$. The experiments include tensile strain tests on unnotched sample and on single edge notched sample (SENT), performed at different strain rates. These results are discussed using strain energy based analyses.

\section{EXPERIMENTAL}

\section{Materials}

Two polymer matrices have been used: a styrene butadiene (SB) and a poly cis-isoprene 1,4 (so called natural rubber NR).

The SBR formulation was chosen from those used in Ramier's work ${ }^{18,30}$. Using the terminology employed in the rubber industry, the contents are given in phr (i.e. gram of product per $100 \mathrm{~g}$ of polymer matrix). SBR is a copolymer, containing $25 \mathrm{wt} \%$ of styrene, 55 wt $\%$ of polybutadiene 1-2, and $20 \mathrm{wt} \%$ of polybutadiene 1-4 (SBR5525-0 supplied by Bayer S.A.). $1.45 \mathrm{phr}$ of 6PPD (diphenylguanidine) are used as antioxidant. The vulcanization system is made of sulfur (1.1 phr introduced), activator agents (1.82 phr of $\mathrm{ZnO}$ and $1.1 \mathrm{phr}$ of 
stearic acid ) and accelerators (1.3 phr of CBS (n-cyclohexyl-2-benzothiazyl-sulfenamide) and $1.45 \mathrm{phr}$ of DPG (diphenylguanidine)). This matrix is filled either with silica or with carbon black (CB). Silica particles (from Rhodia silice, commercial name : Z1165MP®) have a specific BET surface of $160 \mathrm{~m}^{2} / \mathrm{g}$. Silica particles are used non treated or treated with a chemical agents to modify their surface activity, either a covering agent (hexadecyltrimethoxysilane, so called hereafter AR) or a coupling agent (bis(triethoxysilylpropyl)disulfide, so called hereafter AC). The AR treatment enables to increase the polymer mobility at the filler-matrix interface, as evidenced by bound rubber measurements ${ }^{31}$ and to decrease the filler-matrix strength, as evidenced by easier decohesion mechanisms during stretching. ${ }^{30}$ The treatment content was chosen to cover the filler surface, i.e. $3.07 \mathrm{phr}$ of $\mathrm{AR}$ was used or 2.64 of AC. Carbon black added in the present study is a N234® supplied by Cabot with a specific BET surface of $120 \mathrm{~m}^{2} / \mathrm{g}$. Given their respective density, $50 \mathrm{phr}$ of silica or $45 \mathrm{phr}$ of CB corresponds to $20 \%$ vol. fraction. The sample names are given in Table I.

Unfilled and filled natural rubber samples have been obtained by sulfur vulcanisation of natural rubber (Standard rubber Malaysian numer 10) thanks to the use of the following recipe: $4 \mathrm{phr}$ of $\mathrm{ZnO}, 6 \mathrm{phr}$ of $\mathrm{PPD}, 1.75 \mathrm{phr}$ of CBS, and $1.5 \mathrm{phr}$ of sulfur. Only two filler contents have been prepared, corresponding to $20 \%$ volume fraction : $45 \mathrm{phr}$ of carbon black N234® (reference NRCB) and 50 phr of silica Z1165MP® treated with 4phr of bis(triethoxysilylpropyl)tetrasulfide (reference NRSIAC). The sample names are given in Table I.

\section{Processing}


The samples were processed following the Michelin patent of Rauline ${ }^{32}$. The first step is a shearing of the matrix and the incorporation of the fillers in the polymer with that of the antioxidant 6PPD (paraphenylene diamine, $1.45 \mathrm{phr}$ ). This shearing step lasts 5 minutes. Firstly, the matrix is introduced in an internal mixer (the filling is $90 \%$ of the chamber and the rotor speed $50 \mathrm{rpm}$ ) and sheared for a couple of minutes with $2 / 3$ of the filler content. In the case of treated silica, the organosilane molecules are introduced in the same time. The rest of the filler is introduced after few minutes of shearing. After one night at ambient temperature, a second step enables the optimization of the dispersion and of the grafting process initiated during the first step, as well as the incorporation of the $\mathrm{ZnO}$. The third step is the incorporation of the vulcanization system, i.e. sulphur, and the accelerators CBS (ncycloihexyl-2-benzothiazyl-sulfenamide) and DPG (diphenylguanidine), performed in an open mill for 8 minutes, at low temperature $\left(80^{\circ} \mathrm{C}\right)$ to prevent any reaction of the vulcanization system. After one night at ambient temperature, the last step is the vulcanization in a press at $150^{\circ} \mathrm{C}$ (applied pressure of 150 bars) during a time deduced from torque measurements (these measurements are performed during vulcanization in a Monsanto rheometer ; the time of vulcanization is equal to the time needed to obtain $95 \%$ of the maximum torque value). The samples obtained are around $2 \mathrm{~mm}$ thick films.

\section{Tensile tests}

Tensile tests were performed at room temperature on a MTS 1/ME machine equipped with a thermo-regulated chamber. Two kinds of specimen have been used: classical dumbbell shape sample and dumbbell shape sample with a Single Edge Notch (SENT). Geometry of the dumbbell shape and of the notch is shown in Fig. 1. The notch was made with a homemade device equipped with a razor blade in order to obtain reproducible notch. As shown by Hamed and Park ${ }^{21}$, the strength to break the elastomer is dependent on the cut size, even in soft 
gums. This is especially the case for cut length below the sample thickness. On the contrary, Rivlin and Thomas ${ }^{33}$ observed that the tearing energy was independent on cut size. However, they used large cuts, which were substantially greater than the specimen thickness, leading to strain at break as low as $50 \%$ or even lower. Therefore, as a compromise, in order to promote crack deviation, and facilitate its observation, the cut size was fixed to $2 \mathrm{~mm}$.

Three tensile tests were conducted for each experiment. A video system, supplied by Apolor, was used both for measuring the real strain and to get images during the tensile tests, especially during crack initiation and crack propagation. The crosshead speed chosen was either $10 \mathrm{~mm} / \mathrm{min}$ or $250 \mathrm{~mm} / \mathrm{min}$ which corresponds to an initial engineering strain rate of $0.017 \mathrm{~s}^{-1}$ or $0.425 \mathrm{~s}^{-1}$.

The image recording rate of the video equipment was fixed to 2 image/s (for $10 \mathrm{~mm} / \mathrm{min}$ ) or to $5 \mathrm{image} / \mathrm{s}$ (for $250 \mathrm{~mm} / \mathrm{min}$ ). The determination of the critical specimen elongation at which the crack initiates and begins to propagate was done by a careful examination of the video images. Given the image acquisition rate and the crosshead speed, the error on the critical elongation value can be first estimated equal to $\pm 0.07 \mathrm{~mm}$ and to $\pm 0.7 \mathrm{~mm}$ for crosshead speed $10 \mathrm{~mm} / \mathrm{min}$ and $250 \mathrm{~mm} / \mathrm{min}$ respectively. Expressed in engineering strain (stretching value by the sample initial length), it is equal to \pm 0.007 and \pm 0.07 respectively. Of course, this error can be increased by an incorrect interpretation of the images. However, the good reproducibility of the results was checked by a testing of 4 specimens and enabled to estimate that the error made on the engineering strain value at the crack initiation is \pm 0.1 .

\section{RESULTS AND DISCUSSIONS}

\section{SBR filled materials}

The impact of the addition of silica is first evaluated when the matrix is SBR. Figure 2

presents the tensile engineering stress-strain curves at $\dot{\varepsilon} \approx 0.017 \mathrm{~s}^{-1}$, performed with 
unnotched specimens, of the different SBR based materials. Experiments (not presented here) have also been performed at $\dot{\varepsilon} \approx 0.425 \mathrm{~s}^{-1}$. The stress and strain at break, as well as the strain energy densities to rupture $E_{r}$ (calculated as the area below the engineering stress strain curve) are reported in table II. Note that no sample broke in the clamps.

In the case of unfilled SBR, the increase in the strain rate does not strongly increase the stress level since the material is mainly elastic. However, the strain rate has a strong influence on the rupture behavior. An increase in the strain rate increases both stress and strain at break. This corresponds to what was reported and explained by Bueche et al ${ }^{34-36}$ : the rupture is related to the relaxation rate of the material ; the longest the time available for relaxation, the smallest the number of polymer chains which eventually support the stress, and therefore the highest the stress they have individually to support.

As already reported, ${ }^{18,30}$ the addition of silica or CB strongly reinforces the material. The mechanical properties are sensitive to the filler treatment. The use of a coupling (or a covering) agent decreases (increases) the initial modulus because of the modification of the filler-filler and filler-matrix interactions. Moreover, the coupling agent, by creating strong covalent bonds, increases the material hardening, while the covering agent by promoting the interfacial decohesion, decreases it. The addition of the same volume fraction of CB leads to a higher reinforcement level than the one provided by silica treated with a coupling agent.

The lowest sample strength is obtained for the unfilled SBR. The highest is obtained for MCB45. The addition of silica in the same proportion leads to a lower stress at break whatever the silica treatment. The use of a coupling agent decreases the strain at break without decreasing the stress at break, (which is the same as the one of the material filled with untreated silica). The highest elongation at break is found for the materials with silica treated with a covering agent. Both strain rates lead to the same relative position of the different materials in term of stress and strain at break. Given the uncertainties in their values, any 
conclusion on the strain rate influence must be made with caution; however, it seems that CB and AR treated silica leads to an inverted effect of the strain rate increase compared to that observed with the other materials, i.e. it leads to a decrease in the rupture properties. Since the AR treatment is known to promote the polymer mobility in the filler vicinity, ${ }^{31}$ it can be assumed that the strain rate effect on MSIAR is due to the viscoelastic nature of this mechanism. Moreover, such mobility might ease the filler alignment in the stretching direction and therefore lead to better rupture properties for MSIAR than for MSI or MSIAC. Figure 3 presents the stress-strain curves obtained with the SENT specimens. Stress and strain are engineering values. They are calculated as the force divided by the initial sample thickness and the specimen elongation divided by its initial length. Like previously, only the 10 $\mathrm{mm} / \mathrm{min}$ crosshead speed experiments are reported, since the increase in crosshead speed does not change the relative position of the different curves. The engineering stress and strain at break $\varepsilon_{\mathrm{r}}^{\prime}$ and $\sigma_{\mathrm{r}}^{\prime}$ are reported in Table III. In the same table it is reported $\mathrm{E}_{\mathrm{r}}$, the energy calculated from the area under the force displacement curve divided by the initial sample volume. The rank of the different samples in term of rupture behavior is not changed by the notch, for both tested speeds ; this means that the use of unnotched samples gives already useful information on the rupture behavior of the tested materials, as far as the rupture is not initiated in the clamp. However, one can note that the effect of the speed increase is to systematically increase the energy to rupture $\mathrm{E}_{\mathrm{r}}$, i.e. the specificity of MSIAR and MCB45 does not hold in the case of notched specimens. Indeed, the speed increase has the same impact on the filled materials as that observed with unfilled SBR. Thus, the strain localization induced by the notch seems to promote the same rupture mechanisms involved in the rupture of the unfilled material.

Video observation allows visualizing the crack propagation for the different samples. As an illustration, Figure 4a presents different images of the crack growth during the stretching of 
the unfilled SBR. At the beginning of the test, the notch opens and takes a parabolic-like shape. Then at around $100 \%$ engineering strain, the crack appears and begins to propagate. In this case, the crack opening stays symmetric. The crack propagation rate is relatively constant up to a point where the ligament becomes small. Then the crack propagation becomes catastrophic. As seen on the picture taken after the sample break, the SBR crack is lateral, i.e. perpendicular to the stretching direction. An increase of the crosshead speed does not change its crack propagation mode, which stays lateral.

At low CB content, the images are not very different from those obtained with unfilled SBR. A small irregularity can be observed at the beginning of the crack propagation. But this small irregularity does not lead to crack deviation. Conversely, as shown in Figure 5, $45 \mathrm{phr}$ of $\mathrm{CB}$ strongly changes the crack propagation. At the beginning of the test, the notch opens and stays symmetric up to an engineering strain around $75 \%$. Then an irregularity appears, indicating the crack initiation. This makes dissymmetric the propagation at the crack tip and the crack follows a deviated path, as seen in the picture of the broken sample. A higher crosshead speed does not change these observations except that the deviation is more important. Same type of observation can be made with silica filled SBR, whatever the filler treatment (cf. images in Figure 5b for MSIAR). However, the crack deviation is more important with the silica treated with a covering agent.

Different authors proposed to treat the rupture process from an energetic point of view. The advantage of such approach is not to require the knowledge of the stress and strain fields around the crack tip. Thus, various authors have proposed to extend the Griffith Criterion ${ }^{36}$ to the tearing of rubbers and found that the amount of potential energy decrease per unit crack area can remain constant for a given material when a crack starts to propagate. As shown by Andrews ${ }^{38}$ and Rice ${ }^{39}$, a way to estimate this strain energy release rate is to calculate the Jintegral, which is related to the area under a curve of load versus load point displacement. As 
demonstrated by Rivlin and Thomas ${ }^{33}$, in the case of notched samples, this J-integral can be approximated by the relationship :

$$
J=2 k(\lambda) W_{0 \lambda} a
$$

Where $\mathrm{a}$ is the crack length, $\mathrm{W}_{0 \lambda}$ is the uniform strain energy density of the same specimen containing no crack and submitted to the same stretching ratio $\lambda$, and $\mathrm{k}$ is a dimensionless function of $\lambda$. A lot of recent studies have been devoted to a comparison between the Jintegral value directly calculated by Finite Element Method and this equation or equations of the same type. These comparison have been made for different sample geometries. ${ }^{40,41,42,43}$. In the specific case of SENT Specimen, according to Greensmith ${ }^{44} \mathrm{k}(\lambda)$ can be approximated by:

$$
k(\lambda)=\pi \lambda^{-0.5}
$$

Such relation was validated experimentally by Lake ${ }^{45}$ and numerically by Timbrell et al. $^{46}$. Aware that such expression is an approximation which depends on the specimen geometry ${ }^{47}$, we used it only for the calculation of the critical $J_{c}$ values, calculated from equations (1) and (2) at the crack initiation. They are reported in Table III. We have also reported $\mathrm{E}_{1}$ defined as the area under the engineering stress-strain curve, calculated from 0 engineering strain up to the engineering strain estimated at the crack initiation $\left(\varepsilon_{\mathrm{i}}\right)$, and E2 defined as the area under the engineering stress-strain curve calculated from $\varepsilon_{\mathrm{i}}$ up to the engineering strain at break.

The $\mathrm{J}_{\mathrm{c}}$ value of $\mathrm{M}$ is around $3000 \mathrm{~J} / \mathrm{m}^{2}$ and is roughly constant whatever the strain rate. Thus, in the case of unfilled SBR, the difference in strain and stress at break for different strain rate values is more related to crack propagation than to crack initiation. The lowest $J_{c}$ value is found for MSIAC. This suggests that the crack initiation is promoted by the fillers when the filler-matrix interface is strong. Conversely, when the filler-matrix interaction is weaker, like in the case of MSIAR or MSI, the $\mathrm{J}_{\mathrm{c}}$ values at low strain are more important. In addition, an increase of the strain rate leads to a strong decrease of $\mathrm{J}_{\mathrm{c}}$ which becomes lower than that of $\mathrm{M}$ 
and tends toward the Jc values of MSIAC. Thus $\mathrm{J}_{\mathrm{c}}$ appears to be related to energy dissipation processes induced by the filler presence: the most relaxation mechanisms are promoted in the filler-matrix interface vicinity, the highest the $\mathrm{J}_{\mathrm{c}}$ value. These relaxation phenomena are obviously promoted when the filler-matrix interaction are weak, i.e. like in the case of silica treated with a covering agent. Note that there is not much difference between the sample filled with $\mathrm{CB}$ or silica except that $\mathrm{J}_{\mathrm{c}}$ value of MCB45 shows a lower sensitivity to strain rate than $\mathrm{J}_{\mathrm{c}}$ of MSI or MSIAR.

$E_{1}$, values leads to the same comment as the $J_{c}$ value: the lowest is obtained for MSIAC and, in this case, is roughly independent on the elongation rate. The other samples give higher values, especially MSIAR and MCB45. These results were expected since like $\mathrm{J}_{\mathrm{c}}$, $\mathrm{E}_{1}$ is related to the energy stored and dissipated before the crack initiation.

On the other hand, $E_{2}$ is related to the energy needed to propagate the crack up to the sample rupture. The results indicate that the fastest the stretching, the highest the energy required for the crack propagation. In the case of the unfilled matrix, as shown in Table III, $\mathrm{E}_{2}$ value is very small. Given the measurement uncertainty, the strain rate influence is not clear. The addition of few $\mathrm{CB}$ increases $\mathrm{E}_{2}$ value, with still a small influence of the strain rate. Conversely addition of a larger amount of $\mathrm{CB}$ or of silica leads to much higher $\mathrm{E}_{2}$ values, with a much higher sensitivity to strain rate: for the materials filled with 45 or $50 \mathrm{phr}$ of filler, the strain rate increase leads to both an $\mathrm{E}_{2}$ increase and to more important crack deviation. Moreover, the highest $\mathrm{E}_{2}$ value is obtained with the materials with the most important crack deviation (MCB45 and MSIAR). Thus, as expected, $\mathrm{E}_{2}$ is strongly related to the crack deviation. Note also, to support this, that with MSIAR, $E_{2}$ increases, while $J_{c}$ decreases with an increasing strain rate: the latter indicates that the higher the strain rate, the less difficult to initiate the crack, though the more difficult to reach the sample rupture (as indicated by $E_{2}$ and by the crack deviation). The author assumption is that the crack initiation is favored when the 
material has not enough time to relax the rapidly increasing stress concentration at the crack tip. Thus, the introduction of fillers can exacerbate these effects, by promoting relaxation mechanisms, these mechanisms including the reorganization of the filler microstructure, and damage processes such as decohesion or cavitation. Moreover, the use of a coupling agent to treat silica, by strengthening the filler-matrix interactions, inhibits these relaxation mechanisms and therefore attenuate the strain rate influence on the crack initiation.

Conversely, the relaxation mechanisms, which have more time to occur at low strain rate, decreases the strain anisotropy in front of the crack and therefore attenuate the crack deviation. However, the anisotropy can be enhanced by the filler alignement in the stretching direction. Such alignment is made more difficult in the case of MSIAC, due to the presence of the coupling agents. But it might be made easier when the filler is treated with a covering agent, like in MSIAR. This would explain the highest E2, and the more deviated crack path in MSIAR.

To conclude, the strain rate influence on the crack resistance of the SBR composites is the complex result of the viscoelastic behaviour and of the microstructural evolution under strain of these materials, both being strongly inter-related and having consequences different on the crack initiation and on the crack deviation.

\section{NR filled materials}

The influence of the filler type has also been studied with NR. Engineering stress-strain curves obtained on unnotched samples are presented in Figure 6. Stress and strain at break, as well as $E_{r}$, are reported in Table IV. The values found for unfilled NR are weakly influenced by the strain rate. A strain rate increase slightly increases the strain and stress at break as observed previously with SBR samples. A SAXS study previously performed on a NR matrix with the same recipe, showed a beginning of Strain Induced Crystallization (SIC) for draw 
ratio around 3.5 , i.e. a nominal strain around $2.5^{15-16}$. The strain rate in the cited study was $6.410^{-4} \mathrm{~s}^{-1}(0.25 \mathrm{~mm} / \mathrm{min}$ for an initial gauge length of $6.5 \mathrm{~mm})$ while in the present study, the samples are stretched with an initial strain rate of $0.425 \mathrm{~s}^{-1}$ or $0.017 \mathrm{~s}^{-1}$, i.e. 20 times or 1000 times higher, respectively. As shown by Rault ${ }^{48}$, such an increase in strain rate of a 100 factor can increase the strain value at which the materials begins to crystallize of more than $100 \%$. Therefore, in the present study, the SIC in the case of unnotched specimen is likely beginning at a strain around 3.5 for the highest strain rate of 0.4 , and around 2.5 for the strain rate of $0.017 \mathrm{~s}^{-1}$. This is likely at the origin of the difference in the strain at which the hardening begins for both strain rates (cf. Figure 6). However, this also suggests that these materials have partly crystallized before breaking. Thus, the crystallization likely occurs; but it does not improve the rupture properties of the unnotched samples; otherwise, the lowest strain rate, by promoting the crystallization, should lead to the highest strain and stress at break.

When the sample is notched, the strain rate influence is inverted: a lower strain rate leads to a higher elongation at break. The engineering strain at break of the notched sample stretched at $10 \mathrm{~mm} / \mathrm{min}$ is even higher than that of the unnotched specimen (cf. Figure 7 and Table V). Due to the notch presence, strain localization occurs at the crack tip. This promotes crystallization, which becomes high enough to take control of the rupture behaviour. The $\mathrm{J}_{\mathrm{c}}$ value of NR calculated at both crosshead speeds is an order of magnitude higher than that calculated for SBR. As expected, the strain rate increase leads to a decrease of the $\mathrm{J}_{\mathrm{c}}$ value. Thus, the crack initiation is made more difficult at low strain rate, when the material has time to crystallize, and therefore is more resistant to break.

No crack deviation is observed at a crosshead speed of $250 \mathrm{~mm} / \mathrm{min}$, while at $10 \mathrm{~mm} / \mathrm{min}$, one can note a dissymmetry visible on the broken notched sample (cf. Figure 4b). This is consistent with the $E_{2}$ values reported in table $V$ : the highest value is found at low strain rate, 
when the crack path is more tortuous. Note that the $\mathrm{E}_{2}$ values are at least ten times higher than those measured in the case of the SBR materials: this clearly evidences the importance of the SIC mechanisms in the rupture behavior of the notched specimens.

As expected, the introduction of fillers strongly reinforces the NR material (cf. Figure 6 and 7). As seen on the engineering stress-strain curves obtained with unnotched samples, the stress level is much higher, whatever the strain rate. Introduced with nearly the same volume fraction, both fillers give the same reinforcement at engineering strain below 2. Above this strain value, $\mathrm{CB}$ filled samples show a higher hardening than the silica filled materials, with less good rupture properties. In addition, the effect of the strain rate in the rupture behavior of unnotched specimen is not modified by the filler introduction: higher stress and strain at break are obtained at the highest strain rate. Nevertheless, these materials are known to crystallize at a strain around 2.5 when tested at $6.410^{-4}$ strain rate ${ }^{14-16}$. Even considering the higher strain rate in this study, the beginning of crystallization should occur at strain much lower than the strain at break of the samples, and the crystallite content should be significant before the sample rupture. Thus, like for unnotched SBR based samples, it can be concluded that the crystallization process, though its occurrence, is not the main phenomenon controlling the material rupture of unnotched specimen (even if the crystallization has probably an impact on the resistance to crack initiation).

Conversely, for notched samples (cf. Figure 7), as seen previously with unfilled NR, the strain rate decrease leads to an improvement of the rupture properties of the filled materials. This strongly suggests that the kinetic process of crystallisation is involved. Thus, the strain localization induced by the notch promotes the crystallization at the crack tip, which in turn makes more difficult the crack propagation. This phenomenon improves so much the rupture behavior that the engineering stress and strain a break of the notched samples are higher than those measured with unnotched specimens. 
Moreover, as observed with unnotched specimens, the silica filled material has better rupture properties than the $\mathrm{CB}$ filled one. This can hardly be attributed to a more difficult crack initiation, since the introduction of $\mathrm{CB}$ or silica both leads to $\mathrm{J}_{\mathrm{c}}$ value close to those calculated for NR. Thus, like for unfilled NR, the crack initiation is favored at high strain rate, because the crystallization process has less time to occur. The close values obtained for MSIAC and MCB45 can be explained by the very similar crystallization rate of both materials ${ }^{14-16}$.

The main difference between these two samples is their $E_{2}$ value. For both filler types, the introduction of fillers strongly increases it compared to that of NR. $E_{2}$ is also highly sensitive to the strain rate and decreases with increasing speed, especially in the case of NRSIAC. The crack observations are consistent with the calculated $\mathrm{E}_{2}$ values. In both filled materials, and for both stretching speed, the crack is strongly deviated. As shown in Figure 8, the crack opens and takes a parabolic-like form, then two little bumps appear at the crack tip. These bumps develop slowly in the stretching direction from two small longitudinal crack formed on both sides of the crack tip, so called mustache-like cracks. This changes the crack tip geometry which becomes flat, leading to a reduction of the stress concentration. Then, at larger elongation, a second generation of longitudinal crack appears again in the crack tip, and so on until the brutal and deviated crack propagation. This process strongly increases the energy needed for the materials rupture, as indicated by the $\mathrm{E}_{2}$ values.

An explanation of these results is difficult; however one possibility is that the filler-matrix interface of NRSIAC, thought the use of AC, is weaker than that of NRCB: this is suggested by the stress-strain curves of unnotched materials, which show a lower hardening for strain above 3 in the case of NRSIAC. At this level of deformation, the filler-matrix decohesion would ease the filler reorganization and alignement. This, with the combination of the concomitant crystallization, would favors crack deviation and energy dissipation. A higher strain rate would inhibit this microstructural reorganisation, and therefore would lead to less 
difference between NRCB and NRSIAC. In addition, the decohesion mechanism assumed in the silica filled materials might ease the mustache-like formation by the initiation of small cracks

\section{CONCLUSION}

The objective of this work was to study the rupture behavior of elastomers filled with different types of fillers, and in particular the crack initiation and propagation of these materials. Two types of elastomers have been studied: one which crystallizes under strain (NR) and another one which does not crystallize (SBR). Two fillers have been studied: carbon black and silica. The tensile test results as well as the observations of the crack propagation of SENT samples during stretching at different speed have lead to the following conclusions :

- Crack deviation is strongly related to the energy needed to propagate the crack.

- The influence of the filler type or of the matrix type on the resistance to crack initiation can be different from their influence on the resistance to crack propagation (and deviation).

- In terms of rupture energy, NR materials are much more efficient than SBR materials, due to their crystallization ability.

- Whether the tested specimen are notched or unnotched, both SBR and NR matrices present non-deviated crack propagation with a same influence of the strain rate, i.e. an easier rupture when the strain rate decreases. In the case of NR, this unexpected behavior might be due to the high strain rate range studied which does not enable sufficient strain induced crystallization. 
- The introduction of fillers in SBR matrix makes the material more sensitive to strain rate for crack initiation, by enabling more energy dissipation prior to this initiation. In filled NR, crack initiation is mainly controlled by the matrix cristallisation.

- Filler introduction also promotes crack deviation in both matrices. Such crack deviation is not observed with unnotched specimen indicating the importance of strain heterogeneities in the rupture mechanism.

- The crack deviation observed with notched specimens is promoted by large strain rate in the case of filled SBR, while in filled NR, it is promoted by lower strain rate. Thus, the crack deviation in NR is controlled by crystallization, which is a slow process, while it is controlled by polymer chain orientation in SBR, which is hindered by relaxation mechanisms.

- However, in term of energy density at break of the SBR composites, the SBR filled with silica treated with a covering agent is the most efficient, and shows more crack deviation. Thus, a weak interface between the silica and SBR is favorable to better rupture properties. This suggest that crack deviation is the result of relaxation mechanisms involving also the filler structure evolution under strain, this evolution being easier with weak filler-matrix interaction.

- When comparing Silica and CB filled NRs, the highest strain energy to rupture is also obtained with silica. By analogy with NR materials, this might also be explained by the weaker filler-matrix interface in the case of silica filler, though the use of a coupling agent.

The presented results also evidenced the kinetic aspect of the rupture, and of the mechanisms it involves: the polymer relaxation, the crystallization (for NR), and the filler-matrix interaction and decohesion, all of them being strongly interrelated. This evidences the need for a mechanical modeling taking into account all these aspects with their time dependence, if 
one wants a better understanding of the rupture, and in particular of the strain rate influence on the rupture properties.

\section{Acknowledgements}

The authors greatly acknowledge J.M. Chenal and T. Baranger for fruitful discussions. 


\section{References}

1. Thomine, M. PhD-thesis, INSA-Lyon, France. 2004 ; and also Thomine, M.; Degrange, J.M.; Vigier, G. ; Chazeau, L.; Pelletier, J.M.; Kapsa, P.; Guerbe, L.; Dudragne, G. Tribology Int 2007, 40, 405-411.

2. Gent., A.N. Engineering with Rubber, Oxford, England, Hansu Publisher, Oxford University Press. 1992.

3 Tsunoda, K.; Busfield, J.J.C.; Davies, C.K.L; Thomas, A.G. J Mater Sci 2000, 35, 5187.

4. Selden R Prog. Rubber Plast. Technol. 1995, 11:1, 56-83.

5. Busse, W. F. Ind. Eng. Chem. 1934, 26, 1194.

6. Persson, B. N. J.; Albohr, O.; Heinrich, G; Ueba, H. J Phys: Cond Mat 2005, 17, 1071.

7. Flory., P. J Ind Eng Chem 1946, 38, 417.

8. P. J. Flory. J Chem. Phys 1947, 15, 397.

9. Andrews, E. H. J Appl Phys 1961, 32, 3.

10. Gdoutos, E. E.; Daniel, I. M.; Schubel, P. Facta universitatis, Series: Mechanics, Automatic, Control and Robotics 2003, 3, 497.

11. Gent, A. N. Trans. Faraday Soc. 1954, 50, 521.

12. Gent, A. N.; Kawahara , S.; Zhao, J. Rubber Chem. Technol 1998, 71, 668.

13. Gent, A. N.; Zhang, L.Q. J Polym Sci Pt B: Polym. Phys 2001, 39, 811.

14. Trabelsi, S.; Albouy, P. A.; Rault, J. Macromolecules 2002, 35, 1054.

15. Chenal, J. M. ; Chazeau, L.; Bomal, Y.; Gauthier, C. J Polym Sci : Pt B : Polym Phys $2007,45,955$.

16. Chenal, J. M. ; Chazeau, L.; Guy, L.; Bomal, Y.; Gauthier, C. Polymer 2007, 48, 1042.

17. Chenal, J. M. ; Gauthier, C.; Chazeau, L.; Guy, L.; Bomal, Y Polymer 2007, 48, 6893.

18. Ramier, J. Ph. D thesis, INSA-Lyon, France 2004.

19. Hamed, G. R.; Zhao, J. Rubber Chem. Technol. 1998, 71, 157. 
20. Hamed, G. R.; Huang M. Y. Rubber Chem Technol 1998, 71, 846.

21. Hamed, G. R.; Park B. H. Rubber Chem Technol 1999, 72, 946.

22. Hamed, G. R.; Rattanasom, N. Rubber Chem Technol 2002, 75, 935.

23. Hamed, G. R.; Al-Sheneper, A. A. Rubber Chem Technol 2003, 76, 436.

24. Andrews, E.H. Rubber Chem Technol 1963, 36, 325.

25. Borret ,G. M. Ph D thesis., Ecole Polytechnique, France. 2000.

26. Liu, H. ; Lee R.F. ; Donovan J.A. ; Rubber Chem. Technol., 1987, 60, 5, 893

27. Grellmann, W. ; Reincke, K. ; Lach, R. ; Heinrich G. Kautschuk Gummi Kunst., 2001, 54, $7-8,387$.

28 Reincke, K. ; Grellmann, W. ; Klüppel, M. Kautschuk Gummi Kunst., 2009, 62, 246.

29 Reincke, K. ; Grellmann, W. Rubber Chem. Technol., 2004, 77, 662.

30. Ramier, J. ; Chazeau, L. ; Gauthier, C. ; Stelandre, L. ; Guy, L. ; Peuvrel-Disdier, E. J. Mat. Sci. 2007, 42, 19, 8130.

31. Ramier, J. ; Chazeau, L.; Gauthier, C. ; Ladouce, L. ; Bouchereau, M J Polym Sci Pt B : Polym Phys 2005, 44, 143.

32. Rauline R. Eur. Patent 0 501227A1, to Cie Générale des Etablissements MichelinMichelin \& Co, 1992.

33. Rivlin, R. S.; Thomas, A. G. J Polym Sci 1953, 10, 291.

34. Bueche, F. Physical Properties of Polymers, Interscence Publishers, Inc., New York, 1962.

35. Bueche, F. J Appl Polym Sci 1963, 7, 1165.

36. Halphin, J.C.; Bueche, F. J Appl Phys 1964, 35, 3142.

37. Griffith, A .A. Phil Trans R Soc London, Ser A 1920, A221, 163.

38. Andrews, E.H. J Mater Sci 1974, 9, 887.

39. Rice, J.R.; Paris, P.C.; Merkle, J.G. ASTM STP 1978, 536, 213. 
40. Yeoh ,O.H Mech. Mat. 2002, 34, 459.

41. Ait Hocine, N.; Nait Abdelaziz, M.; Mesmacque, G. Int J of Fracture 1998, 94, 321.

42. Ait Hocine, N. ; Nait Abdelaziz, M. ; Imad, A. Int J of Fracture 2002, 117, 1.

43. Ait Hocine, N.; Nait Abdelaziz, M. Int J Fracture 2003, 124, 79.

44. Greensmith, H.N. J Appl Polym Sci 1956, 7, 993.

45. Lake, G.J. Rubber Chem Technol 1995, 66, 435.

46. Timbrell C., Wiehahn, M. ; Cook, G. ; Muhr A.H., Constitutive Models for Rubber II, Busfield and Muhr eds,, swets\&Zeitlinger, Lisse, 2003.

47. Lee, D.J.; Donovan J.A., Theoretical Appl. Fracture Mech. 1985, 4, 137.

48. Rault, J.; Marchal, J.; Judenstein, P.; Albouy, P. A. Macromolecules 2006, 39, 8356. 
Figure captions

Figure 1: Scheme of the SENT sample geometry (dimensions in $\mathrm{mm}$ ).

Figure 2: Tensile engineering (nominal) stress-strain curves of unnotched SBR based samples (crosshead speed $10 \mathrm{~mm} / \mathrm{min} ; \dot{\varepsilon}_{\text {ini }} \approx 0.017 \mathrm{~s}^{-1}$ )

Figure 3: Tensile stress-strain curves of notched SBR based samples (crosshead speed $10 \mathrm{~mm} / \mathrm{min})$

Figure 4: Crack propagation images of: a) M (crosshead speed 10mm/min), and b) NR (crosshead speed $10 \mathrm{~mm} / \mathrm{min}$ ). The white scale bars indicate $5 \mathrm{~mm}$.

Figure 5: Crack propagation images of: a) MCB45 sample (crosshead speed 10mm/min), and b) MSIAR (crosshead speed $10 \mathrm{~mm} / \mathrm{min}$ ). The white scale bars indicate $5 \mathrm{~mm}$.

Figure 6: Tensile engineering stress-strain curves of unnotched NR based samples; crosshead speed is given in parenthesis.

Figure 7: Tensile stress strain curves of notched NR based samples; crosshead speed is given in parenthesis.

Figure 8: crack propagation images of: a) NRCB sample, and b) NRSIAC (crosshead speed $10 \mathrm{~mm} / \mathrm{min}$ ), the black scale bar on the pictures indicates $0.5 \mathrm{~mm}$, the white ones indicate 5 $\mathrm{mm}$. 


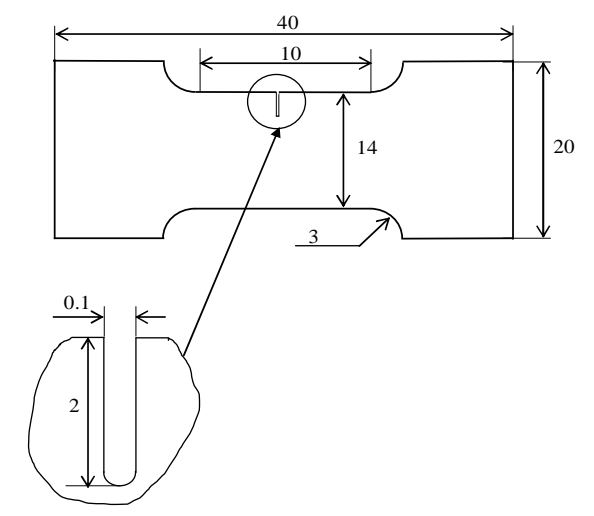

Figure 1: Scheme of the SENT sample geometry (dimensions in mm). 


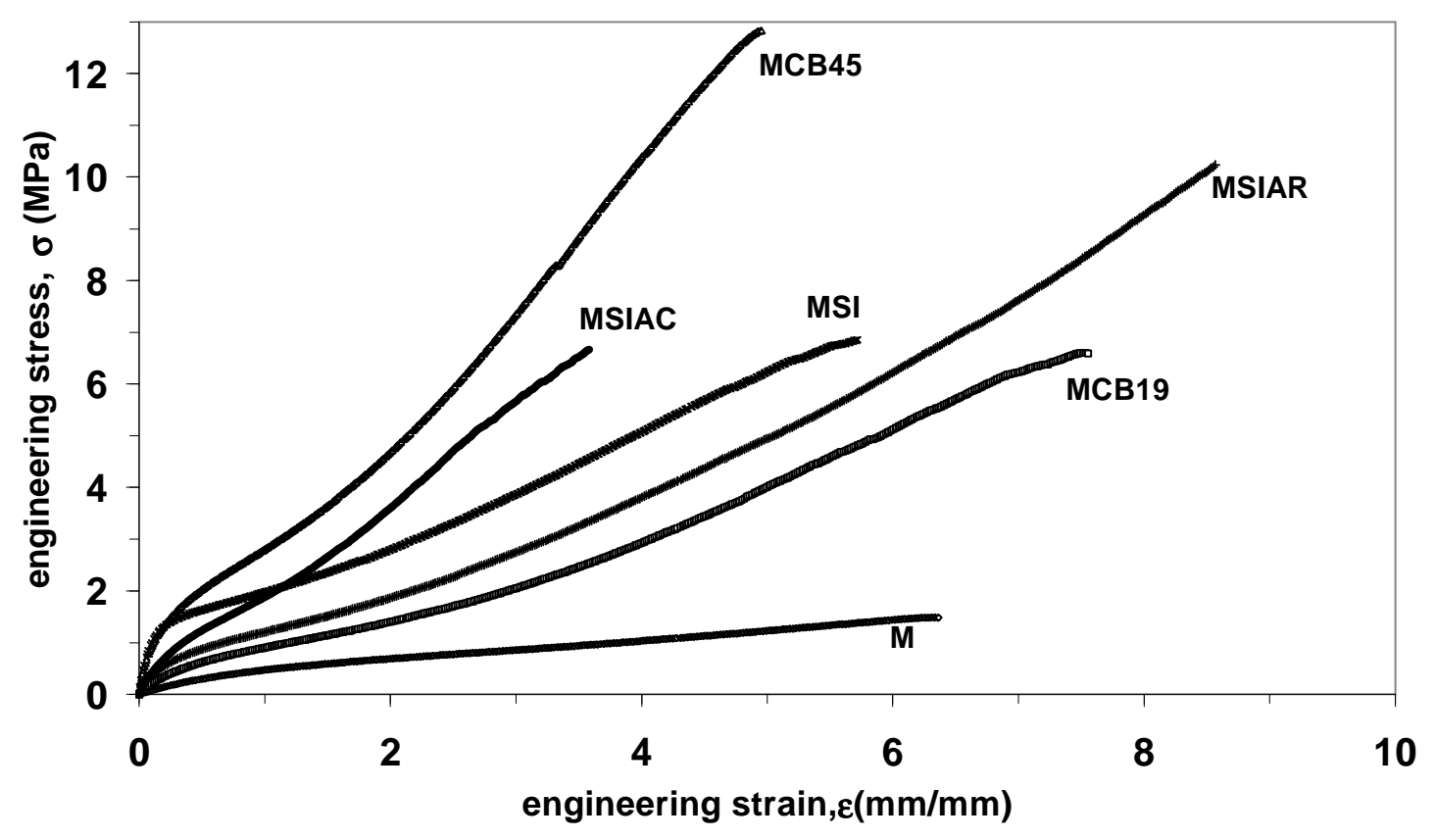

Figure 2: Tensile engineering (nominal) stress-strain curves of unnotched SBR based samples (crosshead speed 10mm/min; $\dot{\varepsilon}_{i n i} \approx 0.017 \mathrm{~s}^{-1}$ ) 


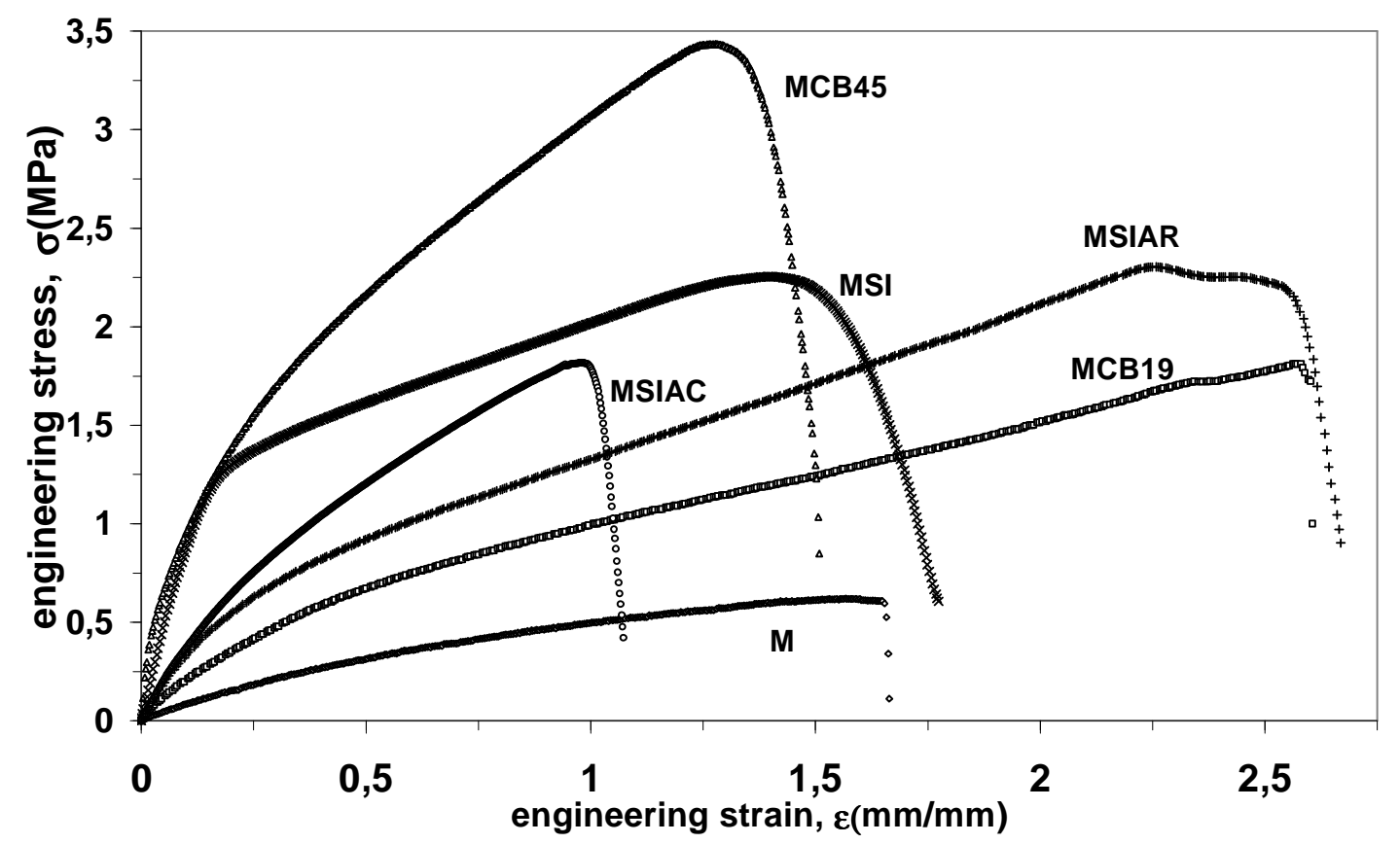

Figure 3: Tensile engineering stress strain curves of notched SBR based samples (crosshead speed 10mm/min) 

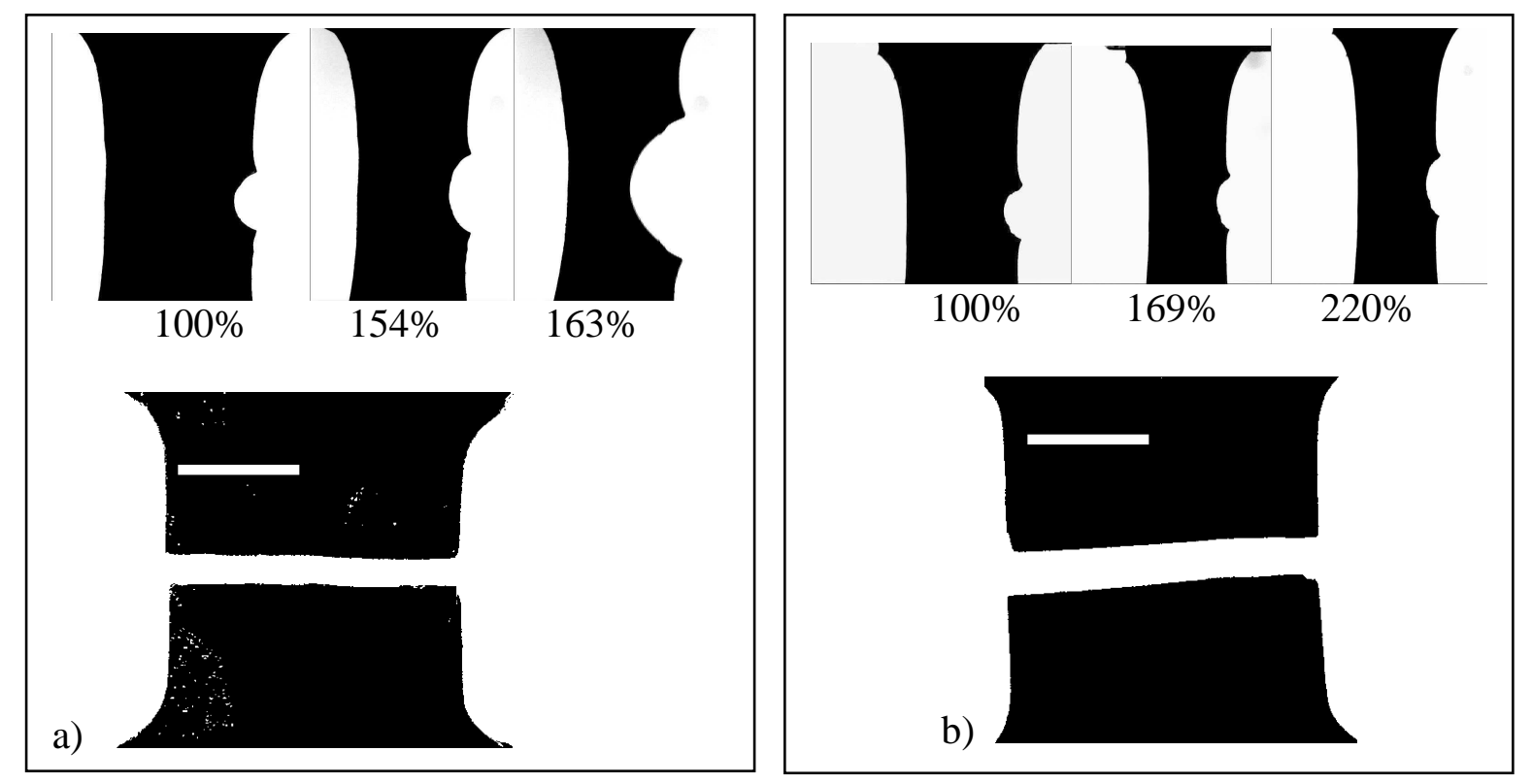

Figure 4: Crack propagation images of a) M sample (crosshead speed $10 \mathrm{~mm} / \mathrm{min}$ ), and

b) of NR (crosshead speed $10 \mathrm{~mm} / \mathrm{min}$ ). White scale bars indicate $5 \mathrm{~mm}$ 

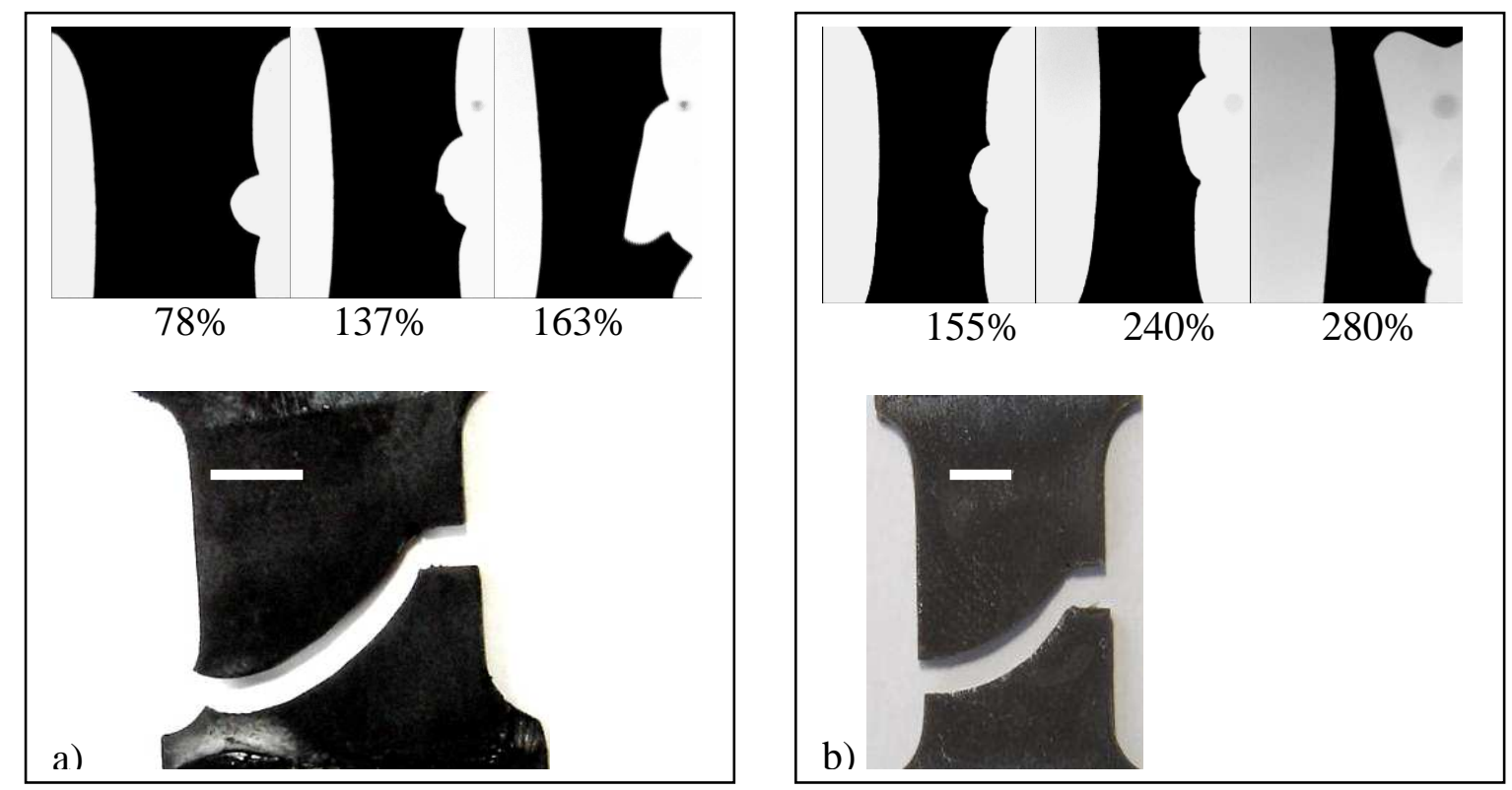

Figure 5: Crack propagation images of a) MCB45 sample (crosshead speed 10mm/min), and b) of MSIAR (crosshead speed $10 \mathrm{~mm} / \mathrm{min}$ ). White scale bars indicate $5 \mathrm{~mm}$. 


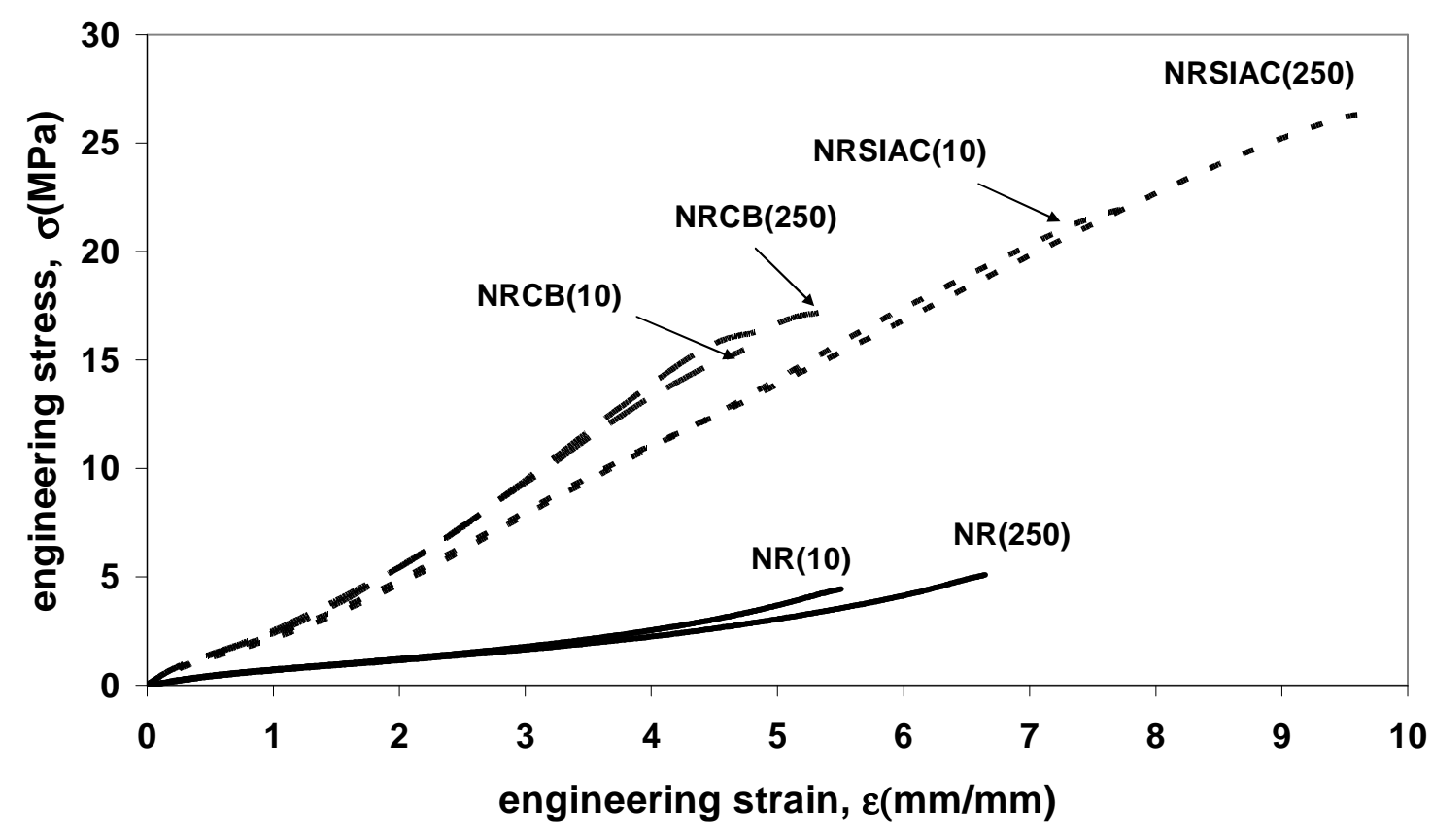

Figure 6: Tensile engineering stress strain curves of unnotched NR based samples; crosshead speed is given in parenthesis. 


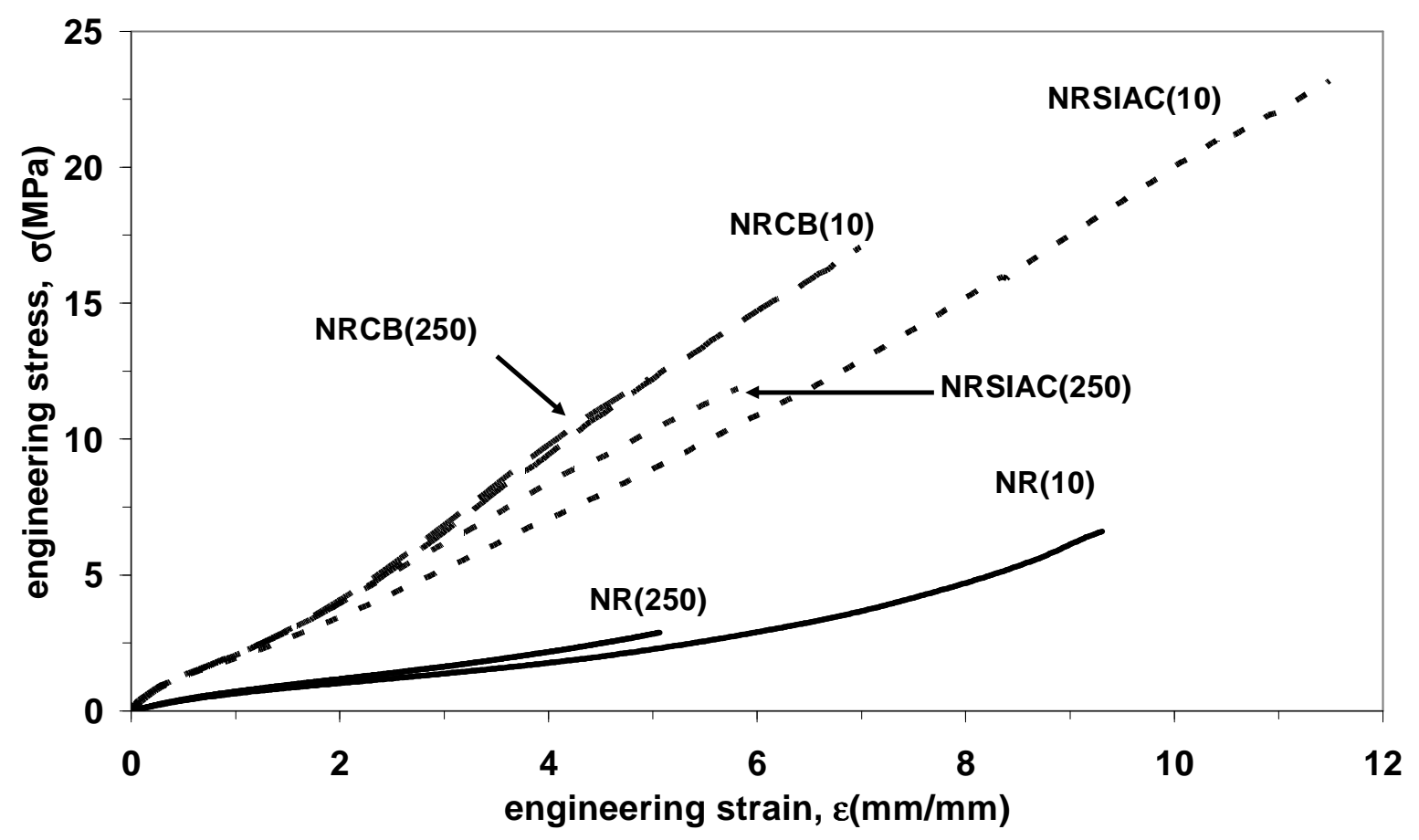

Figure 7: Tensile engineering stress strain curves of notched NR based samples; crosshead speed is given in parenthesis. 

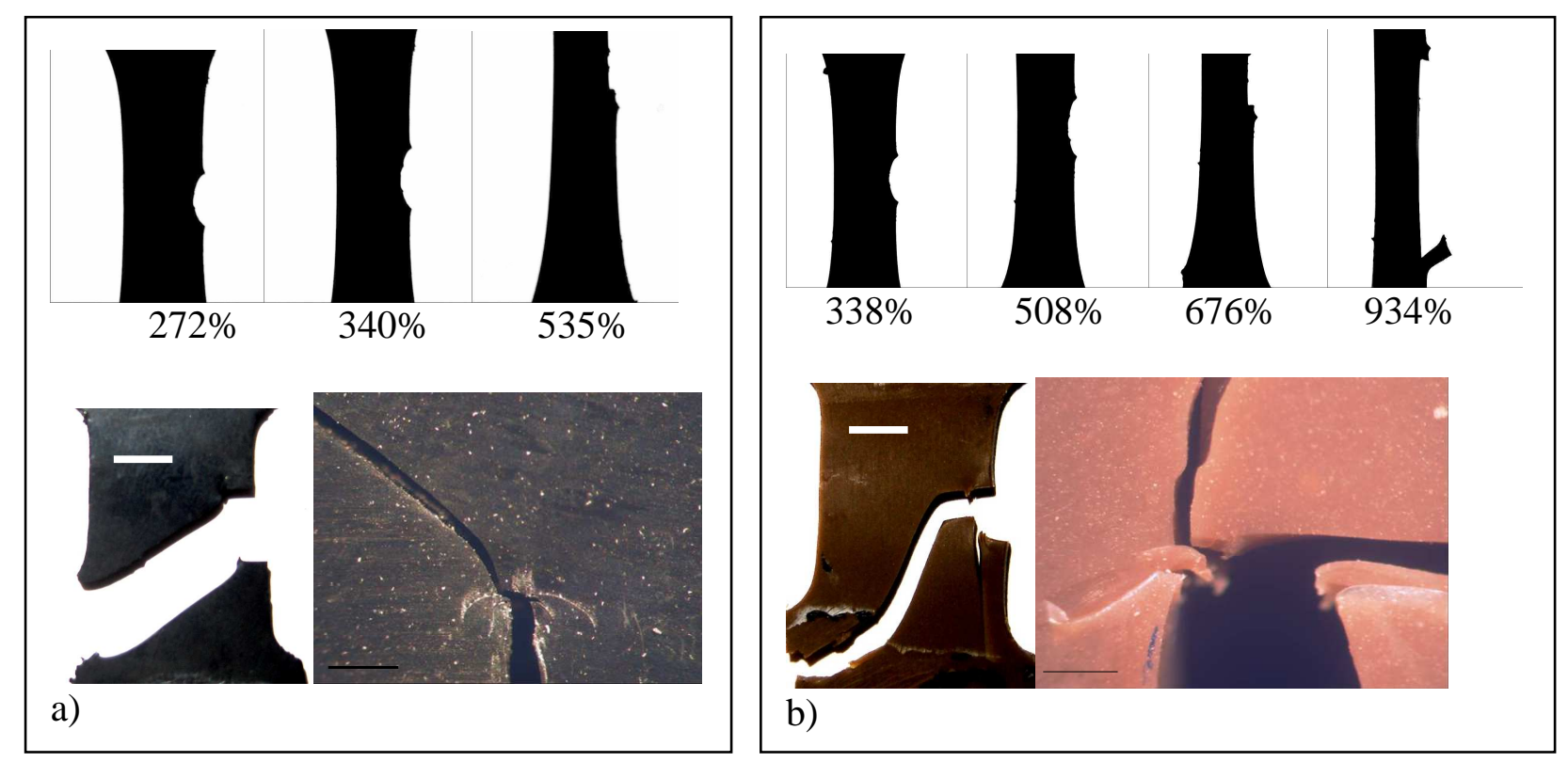

Figure 8: Crack propagation images of a) NRCB sample ,and b) NRSIAC (crosshead speed $10 \mathrm{~mm} / \mathrm{min}$.), the black scale bars on the images indicates $0.5 \mathrm{~mm}$, the white one indicates 5 mm. 


\begin{tabular}{|c|c|c|c|c|}
\hline Filler & Matrix & Surface treatment & Filler content & \\
& & & & \\
\hline Silica & SBR & & & M \\
\hline Silica & SBR & & 50 & MSI \\
\hline Silica & SBR & Coupling & 50 & MSIAC \\
\hline Carbon black & SBR & Covering & 50 & MSIAR \\
\hline Carbon black & SBR & & 45 & MCB45 \\
\hline & NR & & & NR \\
\hline Carbon Black & NR & & 45 & NRCB \\
\hline Silica & NR & Coupling & 50 & \\
\hline
\end{tabular}

Table I : SBR and NR based materials formulation 


\begin{tabular}{|c|c|c|c|c|}
\hline Material & $\mathbf{V}(\mathbf{m m} / \mathbf{m i n})$ & $\boldsymbol{\varepsilon}_{\mathbf{r}}(\mathbf{m m} / \mathbf{m m})$ & $\boldsymbol{\sigma}_{\mathbf{r}}(\mathbf{M P a})$ & $\mathbf{E}_{\mathbf{r}}\left(\mathbf{1 0}^{\mathbf{7}} \mathbf{J} / \mathbf{m}^{\mathbf{3}}\right)$ \\
\hline \multirow{3}{*}{$\mathbf{M}$} & 10 & 6,3 & 1,5 & 0,5 \\
\cline { 2 - 5 } & 250 & 8,1 & 2,7 & 1,1 \\
\hline \multirow{3}{*}{ MCB19 } & 10 & 7,5 & 6,6 & 2,3 \\
\cline { 2 - 5 } MCB45 & 250 & 6,8 & 5,4 & 1,8 \\
\cline { 2 - 5 } & 10 & 5,0 & 12,7 & 3,1 \\
\hline \multirow{3}{*}{ MSI } & 250 & 4,3 & 12,0 & 2,7 \\
\hline \multirow{3}{*}{ MSIAC } & 10 & 5,7 & 6,6 & 2,1 \\
\hline \multirow{3}{*}{ MSIAR } & 250 & 6,3 & 9,0 & 3,0 \\
\cline { 2 - 5 } & 250 & 3,6 & 6,6 & 1,2 \\
\hline & 10 & 4,3 & 9,2 & 1,9 \\
\hline
\end{tabular}

Table II: Data deduced from tensile test on unnotched sample of SBR based materials. 


\begin{tabular}{|c|c|c|c|c|c|c|c|c|}
\hline Material & $\begin{array}{c}\mathrm{V} \\
(\mathrm{mm} / \mathrm{min})\end{array}$ & $\begin{array}{c}\boldsymbol{\varepsilon}_{\mathbf{i}} \\
\pm 0,1\end{array}$ & $\begin{array}{c}\boldsymbol{\varepsilon}_{\mathbf{r}}^{\prime} \\
\pm 0,1\end{array}$ & $\begin{array}{c}\boldsymbol{\sigma}_{\mathbf{r}} \\
\pm 0,1\end{array}$ & $\begin{array}{c}\mathbf{E}_{1} \\
\left(\mathbf{J} / \mathbf{m}^{3}\right) \\
10^{5} \pm 0,5\end{array}$ & $\begin{array}{c}\mathbf{E}_{2} \\
\left(\mathbf{J} / \mathbf{m}^{3}\right) \\
\mathbf{1 0}^{\mathbf{5}} \pm 0,5\end{array}$ & $\begin{array}{c}\mathbf{E}_{\mathbf{r}}^{\prime} \\
\left(\mathbf{J} / \mathbf{m}^{\mathbf{3}}\right) \\
\mathbf{1 0}^{\mathbf{5}} \pm 1\end{array}$ & $\begin{array}{c}\mathbf{J}_{\mathbf{c}} \\
\left(\mathbf{J} / \mathbf{m}^{2}\right) \\
\mathbf{1 0}^{3} \\
\end{array}$ \\
\hline \multirow{2}{*}{ M } & 10 & 1,2 & 1,6 & 0,7 & 3,4 & 2,6 & 6,0 & 3,0 \\
\hline & 250 & 1,0 & 1,7 & 0,8 & 3,4 & 5,1 & 8,5 & 3,4 \\
\hline \multirow{2}{*}{ MCB19 } & 10 & 0,8 & 2,4 & 1,7 & 4 & 18,3 & 22,3 & 3,9 \\
\hline & 250 & 0,5 & 2,0 & 1,6 & 2,2 & 17,8 & 20,0 & 2,4 \\
\hline \multirow{2}{*}{ MCB45 } & 10 & 0,5 & 1,2 & 3,2 & 5,5 & 22,2 & 27,7 & 5,6 \\
\hline & 250 & 0,3 & 1,5 & 4,8 & 4,1 & 49,3 & 53,4 & 4,1 \\
\hline \multirow{2}{*}{ MSI } & 10 & 0,5 & 1,4 & 2,3 & 5,6 & 21,2 & 26,8 & 5,2 \\
\hline & 250 & 0,3 & 1,8 & 3,1 & 3,0 & 49,4 & 52,4 & 2,0 \\
\hline \multirow{2}{*}{ MSIAC } & 10 & 0,3 & 1,1 & 2,0 & 1,9 & 10,7 & 12,6 & 1,9 \\
\hline & 250 & 0,3 & 1,4 & 3,0 & 1,8 & 26,7 & 27,5 & 2,1 \\
\hline \multirow{2}{*}{ MSIAR } & 10 & 0,9 & 2,5 & 2,5 & 7,5 & 31,1 & 38,6 & 5,9 \\
\hline & 250 & 0,4 & 2,6 & 3,2 & 2,7 & 57,2 & 59,9 & 2,2 \\
\hline
\end{tabular}

Table III: Data deduced from tensile test on unnotched sample of SBR based materials. 


\begin{tabular}{|c|r|c|c|r|}
\hline \multirow{2}{*}{ Material } & $\mathbf{V}(\mathbf{m m} / \mathbf{m i n})$ & $\boldsymbol{\varepsilon}_{\mathbf{r}}(\mathbf{m m} / \mathbf{m m})$ & $\boldsymbol{\sigma}_{\mathbf{r}}(\mathbf{M P a})$ & $\begin{array}{l}\mathbf{E}_{\mathbf{r}} \\
\left(\mathbf{1 0}^{\mathbf{7}} \mathbf{J}^{\prime} \mathbf{m}^{\mathbf{3}}\right)\end{array}$ \\
\hline \multirow{3}{*}{ NR } & 10 & 5,5 & 4,4 & 1,0 \\
\cline { 2 - 5 } NRSIAC & 250 & 6,7 & 5,1 & 1,3 \\
\cline { 2 - 5 } & 10 & 7,9 & 22,1 & 8,1 \\
\hline \multirow{2}{*}{ NRCB } & 250 & 9,7 & 26,3 & 3,2 \\
\cline { 2 - 5 } & 10 & 4,5 & 15,5 & 4,3 \\
\hline
\end{tabular}

Table IV : Data deduced from tensile test on unnotched sample of NR based materials 


\begin{tabular}{|c|c|c|c|c|c|c|c|c|}
\hline Material & $\mathrm{V}(\mathbf{m m} / \mathbf{m i n})$ & $\begin{array}{c}\boldsymbol{\varepsilon}_{\mathbf{i}} \\
\pm 0,1\end{array}$ & $\begin{array}{c}\boldsymbol{\varepsilon}_{\mathbf{r}}^{\prime} \\
\pm 0,1\end{array}$ & $\begin{array}{c}\boldsymbol{\sigma}_{\mathbf{r}} \\
\pm 0,1\end{array}$ & $\begin{array}{c}\mathbf{E}_{1} \\
\left(\mathbf{1 0}^{\mathbf{5}} \mathbf{J} / \mathbf{m}^{3}\right) \\
\pm 0,5 \\
\end{array}$ & $\begin{array}{c}\mathbf{E}_{2} \\
\left(10^{5} \mathbf{J}^{3} \mathbf{m}^{3}\right) \\
\pm 0,5\end{array}$ & $\begin{array}{l}E_{r}^{\prime} \\
\left(10^{5} \mathrm{~J} / \mathbf{m}^{3}\right)\end{array}$ & $\begin{array}{l}\mathbf{J}_{\mathbf{c}} \\
\left(10^{3} \mathrm{~J} / \mathbf{m}^{2}\right)\end{array}$ \\
\hline \multirow{2}{*}{ NR } & 10 & 3,7 & 9,3 & 6,7 & 29,6 & 167 & 197 & 23,7 \\
\hline & 250 & 2,5 & 5,1 & 2,9 & 17,3 & 46,2 & 63 & 12,2 \\
\hline \multirow{2}{*}{ NRSIAC } & 10 & 1,6 & 11,0 & 22,4 & 23,8 & 973 & 997 & 22,0 \\
\hline & 250 & 1,3 & 6,3 & 13,2 & 16,5 & 363 & 379 & 16,7 \\
\hline \multirow{2}{*}{ NRCB } & 10 & 1,4 & 7,0 & 17,1 & 18,1 & 480 & 498 & 19,1 \\
\hline & 250 & 1,2 & 6,2 & 13,6 & 15,6 & 306 & 322 & 15,2 \\
\hline
\end{tabular}

Table V: Data deduced from tensile test on notched sample of NR based materials. 